\title{
Hypoxia-induced epithelial VEGF-C/VEGFR-3 upregulation in carcinoma cell lines
}

\author{
NEKTARIA SIMIANTONAKI ${ }^{1}$, CAREN JAYASINGHE ${ }^{1}$, ROMI MICHEL-SCHMIDT, \\ KIRSTEN PETERS, MARIA IRIS HERMANNS and CHARLES JAMES KIRKPATRICK \\ Institute of Pathology, Johannes Gutenberg University, Langenbeckstrasse 1, \\ D-55131 Mainz, Germany
}

Received October 5, 2007; Accepted November 23, 2007

\begin{abstract}
Adaptation to hypoxia, a universal hallmark of carcinomas, is a critical step for tumor cell survival and growth. One of the principal regulators of hypoxia-responsive pathways is the transcription factor hypoxia-inducible factor-1 $\alpha(\mathrm{HIF}-1 \alpha)$. Currently, it is known that tumoral production of members of the vascular endothelial growth factor (VEGF)-family (VEGFs) may promote tumor growth and progression by acting on carcinoma cells that express the cognate receptors (VEGFRs). However, the influence of hypoxia in the formation of such a tumoral VEGF/VEGFR loop is not completely understood. In the present study we examined the potential existence of a HIF- $1 \alpha / \mathrm{VEGF} /$ VEGFR autocrine loop on commonly occuring carcinomas. The experiments were performed on five colorectal carcinoma cell lines, one breast (MCF7) and one lung (A549) adenocarcinoma cell line under normoxic and oxygen stress conditions using HIF- $1 \alpha$-EIA, VEGFs-ELISA as well as RT-PCR and immunofluorescence for VEGFRs. HIF- $1 \alpha$ overexpression was found already after $2 \mathrm{~h}$ of exposure to hypoxia in all above mentioned cell lines, thus documenting that activation of the transcription factor HIF- $1 \alpha$ is an early cellular event. Under hypoxic conditions a significant upregulation and activation of HIF- $1 \alpha$ accompanied by an increased production of VEGF in MCF7 and A549 was observed. The well-differentiated colorectal carcinoma cell lines were 'hypoxia-resistant' showing unchanged levels of HIF- $1 \alpha$ and VEGF under hypoxia. None of the cell lines used in this study expressed the VEGF receptors VEGFR-1 and VEGFR-2 under normoxia and hypoxia. Additionally, all colorectal carcinoma cell lines were negative for VEGFR-3 transcripts in both conditions. However, VEGFR-3 mRNA
\end{abstract}

Correspondence to: Dr Nektaria Simiantonaki, ${ }^{1}$ Present address: Institute of Pathology Klinikum Leverkusen, Am Gesundheitspark 11, D-51137 Leverkusen, Germany

E-mail: simiantonaki@klinikum-lev.de

Key words: VEGF receptors, VEGF family, HIF-1 1 , hypoxia and protein were expressed and under hypoxia overexpressed in MCF7 and A549. Hypoxic cultures of both cell lines secreted in elevated levels the VEGFR-3 ligand VEGF-C but not VEGF-D. Our findings suggest that under hypoxic conditions an autocrine loop between VEGF-C/VEGFR-3 and HIF- $1 \alpha$ is possible in breast carcinoma and lung carcinoma but not in colorectal carcinoma cell lines.

\section{Introduction}

Tumor cells must survive in abnormal enviromental conditions characterized by hypoxia $(1,2)$. The oxygen tension within many solid tumors such carcinomas is substantially less compared to the adjacent normal tissue. In this stress situation a cell selection takes place in favour of the most aggressive cells. In fact, some tumor cells die by apoptosis/necrosis whereas others adapt to the hypoxic conditions by a series of compensatory mechanisms initiating tumor growth and aggressiveness by promoting cell proliferation, invasiveness and angiogenesis. The exact pathomechanisms facilitating the survival of invasive tumor cells are still unclear.

A key regulatory system during hypoxia is the transcription factor, hypoxia inducible factor-1 (HIF-1) (3). HIF-1 is a heterodimer composed of one of the three $\alpha$ subunits (HIF- $1 \alpha$, HIF- $2 \alpha$ or HIF- $3 \alpha$ ) and one HIF-1ß subunit. Although HIF-1ß is constitutively expressed, hypoxiamediated responses are determined by HIF- $\alpha$ subunits. Under hypoxic conditions HIF- $1 \alpha$ translocates to the nucleus and binds to HIF-1ß forming the active HIF-1 complex, which induces target gene expression mostly in a cell-type-specific manner. The product of one of these genes is the vascular endothelial growth factor (VEGF also referred to as VEGF-A), a highly potent pro-angiogenic (paracrine) and pro-survival (autocrine) mediator originally of endothelial cells (4-6). Under hypoxic conditions tumor cells have also been shown to secrete elevated levels of VEGF in a paracrine manner in order to attract and stimulate proliferation of endothelial cells, thus promoting angiogenesis. Interestingly, it becomes more and more apparent that VEGF can also act in an autocrine fashion as a survival factor for the tumor cells themselves and enable their own regulation of survival, growth and progression (7). The biological effects of VEGF are mediated by two related receptor tyrosine kinases, VEGFR-1 
and VEGFR-2 (8). vegf and vegfr- 1 but not vegfr-2 genes harbour consensus HIF-binding sites in their promoter/ enhancer regions $(4,9)$. So far, only a few expression analyses of both receptors and their ligand VEGF have been conducted in neoplastic cells of different tumor types under hypoxia. In colorectal carcinomas VEGF-positive cases tended to have an increased expression of VEGFR-2, which was significantly associated with relatively low systemic oxygenation and tumor progression (10). The VEGF/VEFGR-2 loop was found to be related with HIF- $1 \alpha$ expression and poor prognosis in endometrial carcinomas (11). Das et al have shown, that a hypoxia-driven VEGF/VEGFR-1 autocrine loop interacts with HIF- $1 \alpha$ in neuroblastoma and is required for cell survival, drug resistance and angiogenesis (12).

Two other members of the VEGF family (VEGFs), VEGF-C and VEGF-D stimulate growth of vascular and lymphatic endothelial cells by signaling through the tyrosine kinase receptors VEGFR-2 and VEGFR-3 (13). Both factors are upregulated in many malignant tumors, including colorectal, breast and lung carcinomas (14-16). VEGFR-3 is mostly found on the lymphatic endothelium but it is also expressed in a variety of human malignancies (17). Recent data provide evidence for a possible role of HIF- $1 \alpha$ in tumor lymphangiogenesis by regulating the lymphatic vascular endothelial growth factors VEGF-C in breast ductal carcinomas and esophageal squamous cell to harbour a hypoxia-responsive sequence (21). Until now the role of hypoxia-induced VEGF-D has only been investigated in breast cancer $(19,22)$. Thus, Currie et al reported a significant HIF-1 $\alpha /$ VEGF-D correlation in neoplastic human breast tissues (22).

Tumor cells represent a major source of VEGFs, which may form an autocrine link with VEGF receptors (VEGFRs) expressed on tumor cells themselves. Although during hypoxia such an autocrine VEGF/VEGFRs and HIF-1 $\alpha$ loop may contribute to cell survival it is still practically unknown whether this possible link exists in diverse carcinomas. The aim of this study was to investigate the potential existence of a HIF-1 $\alpha /$ VEGFs/VEGFRs axis in vitro in commonly occurring carcinomas, especially in colorectal carcinomas. For this reason, we examined the expression patterns of these three compontents on five colorectal carcinoma cell lines, one breast (MCF-7) and one lung (A549) adenocarcinoma cell line under normoxic and hypoxic conditions.

\section{Materials and methods}

Cell culture. Tumor cell lines (colorectal carcinoma cell linesSW620, SW837, SW948, CX-1 and HRT18-as well as the breast carcinoma cell line MCF7 and the lung carcinoma cell line A549) were grown in RPMI-1640 medium supplemented with Glutamax (Sigma), 10\% heat deactivated FCS (Gibco), $1 \%$ penicillin (Gibco) and $1 \%$ streptomycin (Gibco) at $37^{\circ} \mathrm{C}$ with $5 \% \mathrm{CO}_{2}$. After growing to subconfluence tumor cells were seeded onto fibronectin-coated 96-well microtiter plates, fresh medium was added and the cells were exposed to normoxia $\left(21 \% \mathrm{O}_{2}\right)$, hypoxia and anoxia. Hypoxia was induced by setting the oxygen content at $3 \% \mathrm{O}_{2}$. Anoxia (nearly $0 \% \mathrm{O}_{2}$ ) was induced by using the AneroGen ${ }^{\mathrm{TM}}$ Compact system (Oxoid, Wesel, Germany).
Quantification of HIF-1 a protein by enzyme immunoassay (HIF-1 $\alpha$-EIA). After exposure to the different culture conditions (normoxia, hypoxia and anoxia) the cells were fixed in buffered $3.7 \%$ paraformaldehyde for $15 \mathrm{~min}$ at room temperature. After three washes with PBS the tumor cells were permeabilized with PBS-buffered $0.1 \%$ Triton X-100 (for $5 \mathrm{~min}$ at room temperature) and incubated with blocking buffer (Boehringer Mannheim, Germany) containing 1\% $\mathrm{H}_{2} \mathrm{O}_{2}$ at $37^{\circ} \mathrm{C}$ for $30 \mathrm{~min}$. Subsequently, monoclonal antiHIF-1 $\alpha$ (IgG1, BD Transduction Laboratories, Heidelberg, Germany) was added at a dilution of 1:100 for $60 \mathrm{~min}$. After three washes with PBS the cells were exposed to the second antibody, biotinylated goat-anti-mouse IgG1 (Amersham, Freiburg, Germany) at a dilution of 1:1000. Using a biotinstreptavidin-system (Amersham) an increased sensitivity was achieved. The color reaction test was performed using peroxidase-catalyzed o-phenyldiamine. The reaction was stopped by the addition of $3 \mathrm{M} \mathrm{HCl}$. Light extinction was determined with a computer-controlled microplate reader at $492 \mathrm{~nm}$. We repeated the experiments five times, to ensure the reproducibility of results.

Immunfluorescence. Tumor cells were seeded onto fibronectin-coated glass chamber-slides (LabTek II CC2, Nunc, Wiesbaden, Germany). After growing to subconfluence cells were exposed to the specific cell culture conditions (normoxia, hypoxia and anoxia). After exposure time cells were fixed with buffered $3.7 \%$ paraformaldehyde (15 min, room temperature). Mouse monoclonal anti-HIF-1 $\alpha$ (BD Transduction Laboratories) and rabbit polyclonal antiVEGFR-3 (Chemicon) were used as primary antibodies. Alexa Fluor 488 goat anti-mouse and donkey anti-rabbit (Eugene, OR, USA) were used as secondary antibodies. Nuclear staining was performed with Hoechst 33342 (Sigma). Fluorescence labeled cells were covered with GelMount (Biomeda Corp/Natutec, Frankfurt, Germany).

VEGFs-ELISA. After an incubation time of $24 \mathrm{~h}$ under the different culture conditions (normoxia-hypoxia) the supernatants of the 96-well plates were harvested and VEGF-A, VEGF-C and VEGF-D ELISA was performed according to the manufacturer's instructions (R\&D Systems, Wiesbaden, Germany).

Semiquantitative reverse transcription- $P C R$. RNA isolation was performed using the RNeasy Kit (Qiagen, Hilden, Germany) in accordance with the manufacturer's protocols. $ß$-actin and VEGFR transcripts were analyzed by RT-PCR. RT was performed with the help of the Omniscript RT Kit (Qiagen) in accordance with the manufacturer's manual. As a template for the specific PCR reactions $2 \mu 1$ of the cDNApool synthesized was used. To amplify the $\beta$-actin specific fragment, 574 base pair (bp), the primers 5'-GAC CTG ACT GAC TAC CTC ATG A-3' (forward) and 5'-AGC ATT TGC GGT GGA CGA TGG AG-3' (reverse) were used. Amplification of the human VEGFR-1 specific fragment, $441 \mathrm{bp}$, was performed using the primers 5'-GCA CCT TGG TTG TGG CTG A-3' (forward) and 5'-GGT TTC GCA GGA GGT ATG GTG-3' (reverse). Amplification of the human VEGFR-2 specific fragment, $473 \mathrm{bp}$, was performed using 

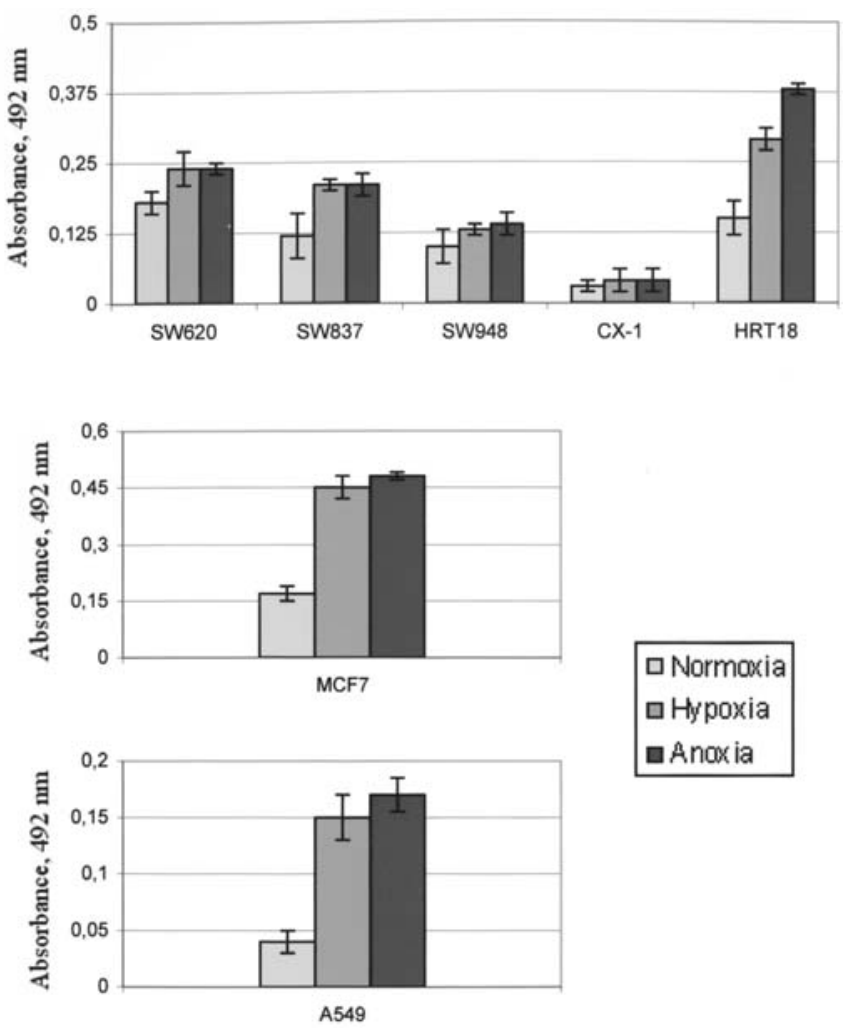

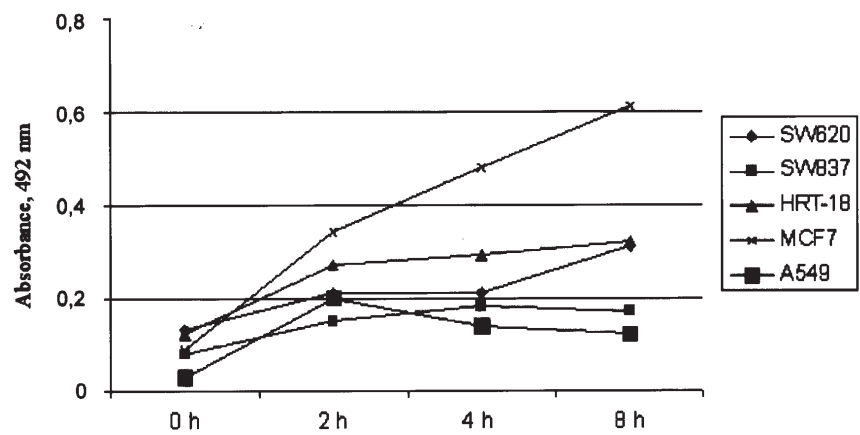

Figure 2. Kinetics of HIF-1 $\alpha$ protein expression, determined by EIA 0,2,4 and $8 \mathrm{~h}$ after exposure to hypoxia in the colorectal carcinoma cell lines SW620, SW837 and HRT-18 as well as MCF7 and A549 $(n=5$, mean values). A significant upregulation of HIF-1 $\alpha$ levels is visible in all cell lines already $2 \mathrm{~h}$ after hypoxic exposure. The elevated levels persist constant in SW837, HRT-18 and A549 and increase gradually in SW620 and MCF7 after 4 and $8 \mathrm{~h}$.

one lung (A549) adenocarcinoma cell line. Three colorectal carcinoma cell lines (SW620, SW837 and HRT-18), MCF7 and A549 showed a significant upregulation of HIF-1 $\alpha$ under hypoxia and anoxia (Fig. 1). Notably, the effects of both conditions were similar except for HRT-18, in which anoxia resulted in a progressive increase of HIF-1 $\alpha$ expression. The HIF- $1 \alpha$ levels of two colorectal carcinoma cell lines (CX-1 and SW948) remained unchanged. Consequently, hypoxia leads to a HIF-1 $\alpha$ upregulation in malignant cells independent of the histogenetic origin, but in this context, especially in the case of colorectal carcinoma 'hypoxia-resistant' cell lines also exist. Considering the kinetics of the expression process we monitored the expression pattern at four different timepoints $(0,2,4$ and $8 \mathrm{~h}$ after hypoxia exposure) (Fig. 2). A significant upregulation of the HIF- $1 \alpha$ level was visible already after $2 \mathrm{~h}$ in all 'hypoxia-sensitive' cell lines. In three cell lines (HRT-18, SW837 and A549) the elevated levels remained constant 4 and $8 \mathrm{~h}$ after hypoxic exposure. In the cell lines SW620 and MCF7, HIF-1 $\alpha$ expression was increased gradually with exposure time. The detection of HIF- $1 \alpha$ protein by immunofluorescence staining revealed no staining in the normoxic tumor cells (Fig. 3A). After exposure to hypoxia for $2 \mathrm{~h}$ a marked nuclear expression of HIF-1 $\alpha$ was detectable in 'hypoxia-sensitive' cell lines (Fig. 3B-F).

Induction of VEGF expression in diverse carcinomas but not of its receptors VEGFR-1 and VEGFR-2 by hypoxia. The second link of a potential HIF-1 $\alpha /$ VEGFs/VEGFRs axis is the tumoral production and secretion of vascular growth factors. Notably, the activation of VEGF gene transcription under hypoxia is mediated by HIF-1 binding to a hypoxiaresponse element (HRE) within the VEGF promoter, resulting in increased gene transcription (4). Interestingly, VEGF was detectable by ELISA in supernatants from all investigated cell cultures under normoxic conditions, although the amount was small in 6/7 tumor lines (122-273 pg/ml) (Fig. 4). After exposure of MCF7 and A549 to hypoxia or anoxia (3\% and nearly $0 \%$ ) for $24 \mathrm{~h}$ VEGF protein levels increased twice to 3 -fold in an oxygen concentration-dependent manner (normoxia: $21 \%$, hypoxia: $3 \%$ and anoxia: nearly $0 \%$ ) on five colorectal carcinoma cell lines, one breast (MCF7) and 

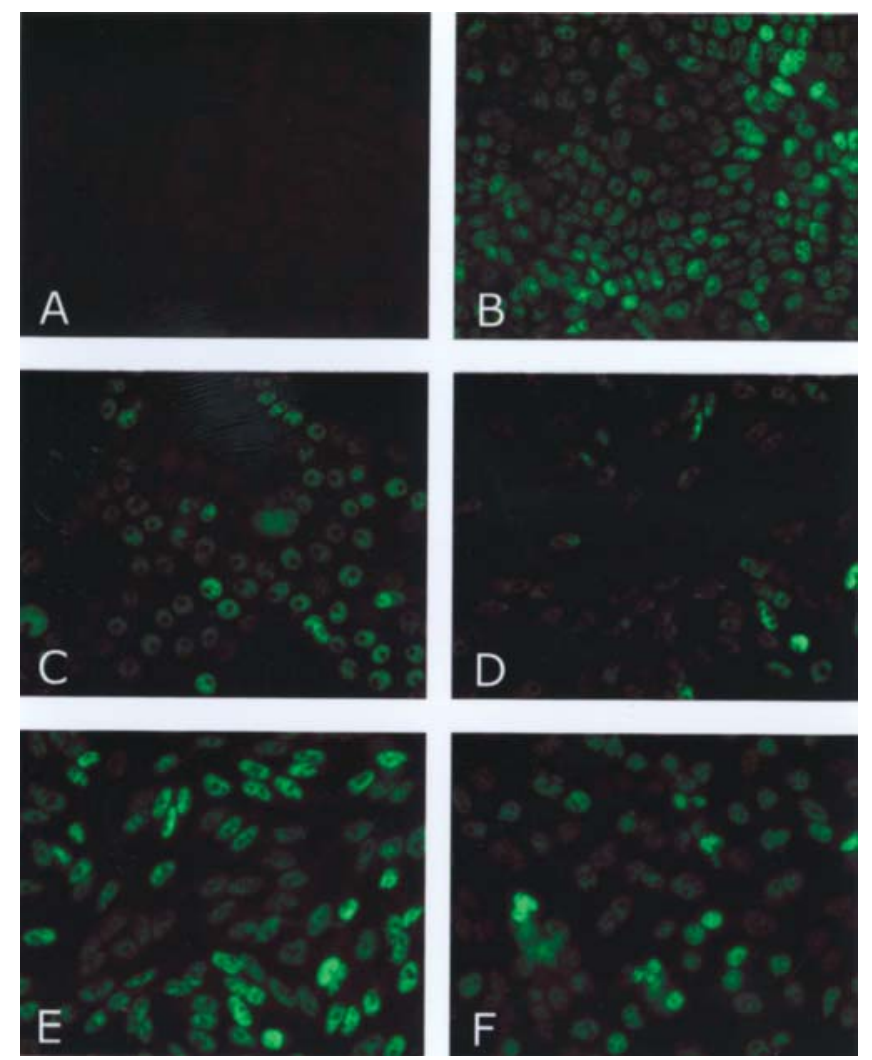

Figure 3. Detection of HIF-1 $\alpha$ protein by immunofluorescence. (A) Absent HIF-1 $\alpha$ nuclear expression on HRT-18 under normoxia. (B-F) HIF- $1 \alpha$ nuclear expression $2 \mathrm{~h}$ after hypoxia exposure on HRT18 (B), SW837 (C), SW620 (D), MCF7 (E) and A549 (F).

(273 pg/ml vs. $495 \mathrm{pg} / \mathrm{ml}$ under hypoxia vs. $813 \mathrm{pg} / \mathrm{ml}$ under anoxia in MCF7, $122 \mathrm{pg} / \mathrm{ml}$ vs. $170 \mathrm{pg} / \mathrm{ml}$ under hypoxia vs. $245 \mathrm{pg} / \mathrm{ml}$ under anoxia in A549). In the colorectal carcinoma cell lines SW620 and SW837 an increased production of VEGF was also observed without significant differences between hypoxia and anoxia (172 pg/ml vs. $236 \mathrm{pg} / \mathrm{ml}$ under hypoxia vs. $260 \mathrm{pg} / \mathrm{ml}$ under anoxia in SW620, $247 \mathrm{pg} / \mathrm{ml} \mathrm{vs}$. $403 \mathrm{pg} / \mathrm{ml}$ under hypoxia vs. $445 \mathrm{pg} / \mathrm{ml}$ under anoxia in SW837). HRT-18, characterized by relatively high amounts of VEGF in normoxia secreted equal levels in the oxygen withdrawal situation $(636 \mathrm{pg} / \mathrm{ml}$ vs. $556 \mathrm{pg} / \mathrm{ml}$ and $592 \mathrm{pg} / \mathrm{ml}$ under hypoxia/anoxia). It should be emphasized that neither CX-1 nor SW948, characterized by lack of HIF-1 $\alpha$ upregulation under hypoxia/anoxia, showed modified VEGF production under these conditions $(207 \mathrm{pg} / \mathrm{ml} \mathrm{vs} .248 \mathrm{pg} / \mathrm{ml}$ under hypoxia vs. $270 \mathrm{pg} / \mathrm{ml}$ under anoxia in CX-1, $230 \mathrm{pg} / \mathrm{ml}$ vs. $185 \mathrm{pg} / \mathrm{ml}$ under hypoxia vs. $159 \mathrm{pg} / \mathrm{ml}$ under anoxia in SW948). These findings suggest that hypoxia leads to a HIF- $1 \alpha$-associated VEGF production in malignant cells independent of the histogenetic origin. Additionally, under hypoxic conditions a significant upregulation of HIF- $1 \alpha$ is not necessarily accompanied by an increased production of VEGF, especially in neoplastic cells with relatively high constitutive amounts of native VEGF.

To determine whether VEGF may form an autocrine loop with its receptors VEGFR-1 and VEGFR-2 expressed on tumor cells themselves we examined their transcription using RT-PCR (Fig. 5). As a positive control for VEGFR-1
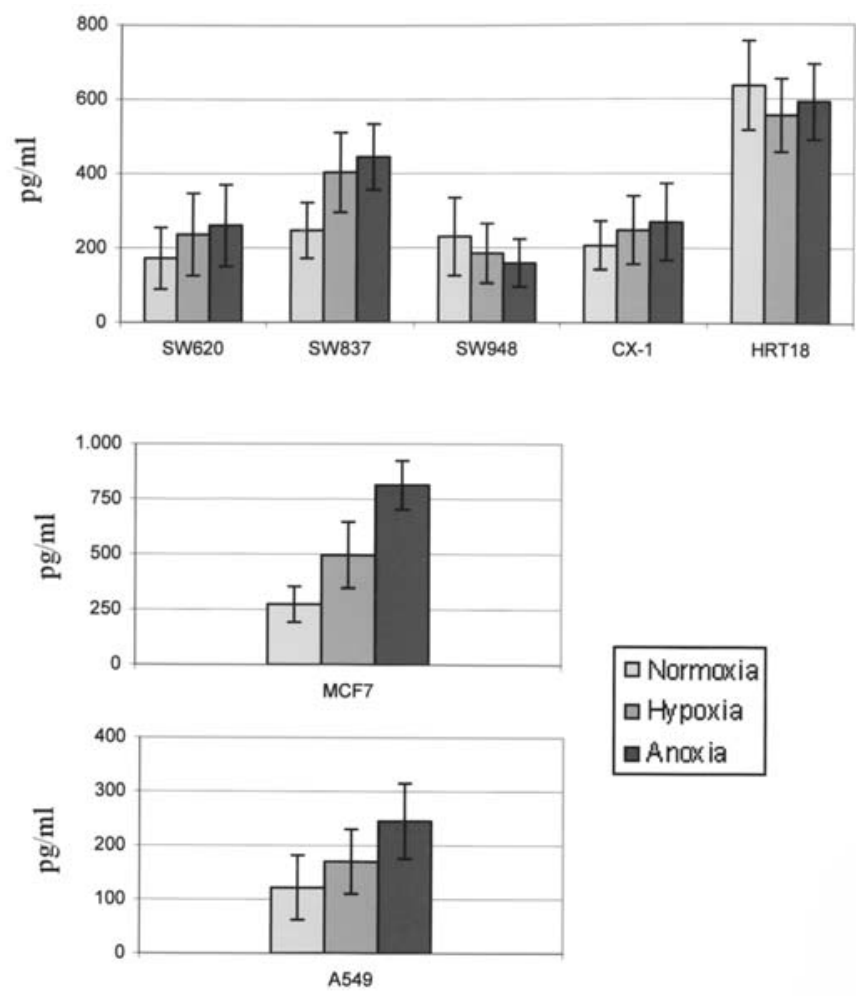

\begin{tabular}{|l|}
\hline Normoxia \\
$\square$ Hypoxia \\
$\square$ Anoxia
\end{tabular}

Figure 4. Determination of VEGF concentrations by ELISA in five colorectal carcinoma cell lines, MCF7 and A549 under normoxic conditions and after exposure to hypoxia and anoxia $(n=5$, mean values \pm standard error). SW620 and SW837 show a significant increased VEGF production under oxygen stress conditions without differences between hypoxia and anoxia. HRT-18 is characterized by relative high constitutive VEGF expression, which remains unchanged under hypoxia/anoxia. After exposure of MCF7 and A549 to hypoxia/anoxia VEGF protein levels significantly increase in an oxygen concentration-dependent manner.

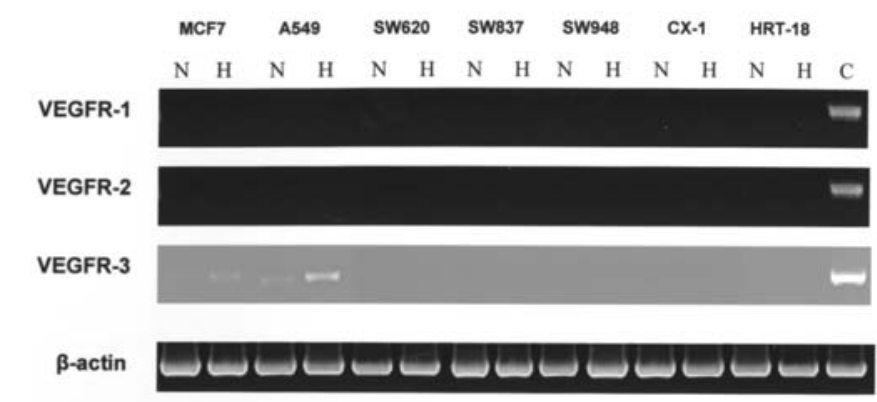

Figure 5. RT-PCR analysis of VEGFRs expression in five colorectal carcinoma cell lines, MCF7 and A549 under normoxia (N) and hypoxia (H). VEGFR-3 m-RNA overexpression is detected in MCF7 and A549 under hypoxia. All cell lines are negative for VEGFR-1 and VEGFR-2 transcripts independent of oxygen concentration conditions. The quality of the reaction was judged upon amplification of a specific B-actin fragment. As control of the reaction $(\mathrm{C})$ the human colonic microvascular endothelial cells (HCMEC) were used.

and VEGFR-2 expression the human colonic microvascular cell line HCMEC was used. All investigated cell lines were negative for the VEGFR-1 and VEGFR-2 transcripts under normoxic conditions and remained negative under hypoxia. Consequently, in these carcinoma cell lines an autocrine 

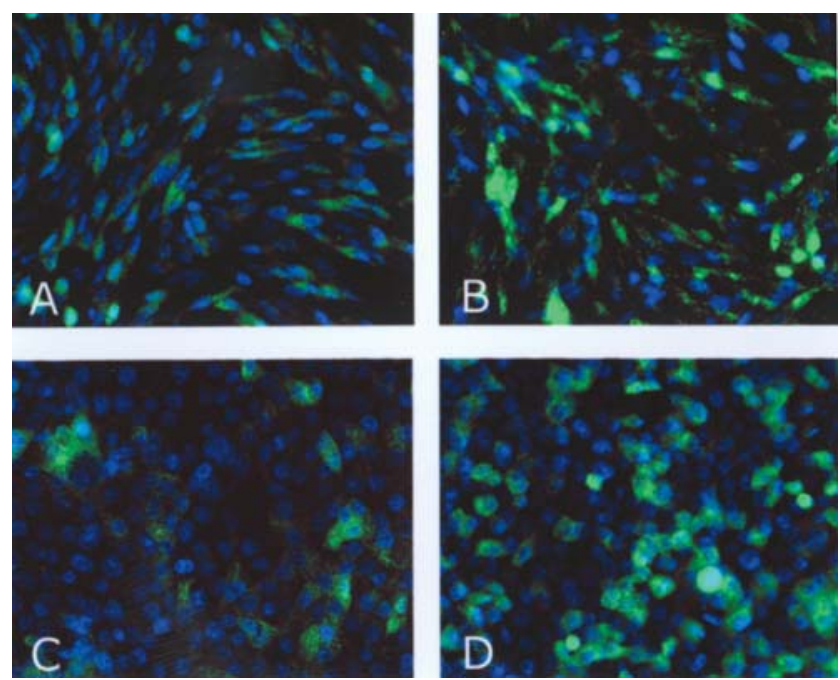

Figure 6. Detection of VEGFR-3 protein in MCF7 (A and B) and A549 $(\mathrm{C}$ and $\mathrm{D})$ by immunofluorescence. VEGFR-3 is overexpressed in both cell lines under hypoxia (B and D).
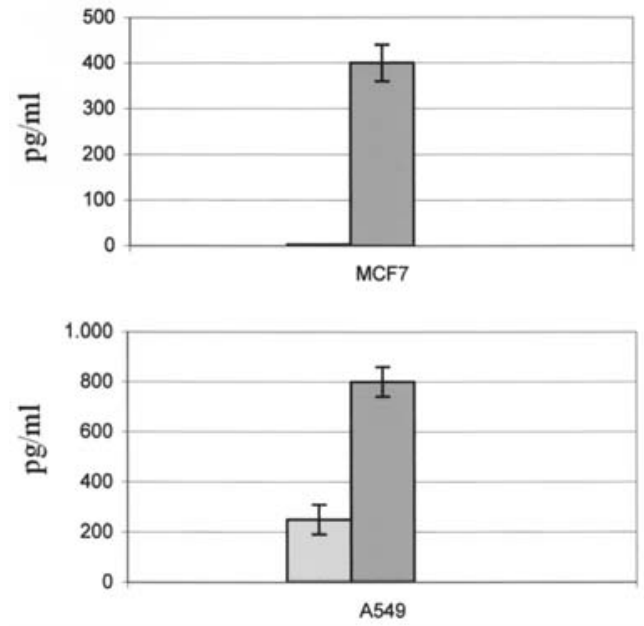

$\square$ Normoxia

口 Hypoxia

Figure 7. Determination of VEGF-C concentrations by ELISA in MCF7 and A549 under normoxic conditions and after exposure to hypoxia $(n=5$, mean values \pm standard error). After exposure of MCF7 and A549 to hypoxia VEGF-C protein levels significantly increase.

loop between VEGF/VEGFR-1 or VEGF/VEGFR-2 is not possible.

Expession of VEGF-C and its receptor VEGFR-3 in MCF7 and $A 549$ but not in colorectal carcinoma cell lines. The results described above clearly indicated that a co-expression of VEGF and its receptors does not exist in normoxic or in hypoxic circumstances. In the next step we addressed the question of whether VEGFR-3, another member of the same family of receptor tyrosine kinases, but not a receptor for VEGF, is expressed by the examined cell lines. For this reason VEGFR-3 expression was investigated in the above cell lines using RT-PCR. As shown in Fig. 5 VEGFR-3 mRNA was only expressed in MCF7 and A549 but not in the colorectal carcinoma cell lines under normoxia and hypoxia.
In both cell lines hypoxia induced an overexpression of this receptor. These data were congruent with the results obtained by immunofluorescence at the protein level (Fig. 6). Hypoxic exposure resulted in enhanced transcription and translation of VEGFR-3 in the breast and lung adenocarcinoma cell lines. Since VEGF-C and VEGF-D are both ligands of VEGFR-3, subsequently the expression of both were tested by ELISA. Significantly higher levels of VEGF-C were found under hypoxia in MCF7 and A549 tumor cells, compared with the normoxic condition (0 vs. $400 \mathrm{pg} / \mathrm{ml}$ under hypoxia in MCF7, $250 \mathrm{pg} / \mathrm{ml}$ vs. $800 \mathrm{pg} / \mathrm{ml}$ under hypoxia in A549) (Fig. 7). In contrast, none of the tumor cells expressed VEGF-D, whether under normoxia or under hypoxia (data not shown). The minimum detectable limit of the VEGF-D ELISA kit was $11.4 \mathrm{pg} / \mathrm{ml}$. In summary, the existence of a VEGF-C/VEGFR-3 autocrine loop in MCF7 and A549 carcinoma cells is possible.

\section{Discussion}

Adaptation to hypoxia is a critical step for tumor cell survival and growth. Currently, it is known that tumoral production of cytokines of the VEGF-family may promote tumor growth and progression by acting on carcinoma cells that express the cognate receptors. However, the influence of hypoxia in the formation of such a tumoral VEGFs/VEGFRs loop is not satisfactorily investigated. In this context the present study was designed to clarify the potential existence of such a HIF-1 $\alpha / \mathrm{VEGF} / \mathrm{VEGFR}$ autocrine loop in commonly occuring tumors, especially on colorectal carcinomas.

Except for the well-differentiated colorectal carcinoma cell line CX-1 constitutive expression of HIF-1 $\alpha$ protein was a general phenomenon under normoxic conditions in the investigated tumor lines. However, a simultaneous nuclear localization representing the active form of this transcription factor was not observed. These findings are consistent with the data published by other groups and support the hypothesis that genetic alterations in key suppressors or oncogenes increase synthesis or stability of HIF-1 $\alpha$ in cancer cells, which in turn results in its expression in non-hypoxic conditions $(23,24)$. Hypoxia-induced VEGF overexpression mediated by HIF- $1 \alpha$ in colorectal, lung and breast carcinoma cells in vitro is well documented (25-29). In accordance with this observation in our study three of the five investigated colorectal carcinoma cell lines, the breast cancer cell line MCF7 and the lung carcinoma cell line A549 showed a significant upregulation and nuclear translocation of HIF- $1 \alpha$ under hypoxia. HIF-1 $\alpha$ overexpression was found already $2 \mathrm{~h}$ after exposure to hypoxia in all above mentioned cell lines documenting that activation of the transcription factor HIF- $1 \alpha$ is an early cellular event. With the exception of HRT-18, these cell lines also demonstrated an increased production of VEGF. Thus, under hypoxic conditions a significant upregulation of HIF-1 $\alpha$ is not necessarily accompanied by a significant increased production of VEGF, especially if constitutive tumoral VEGF production is relatively high. In the well-differentiated colorectal carcinoma cell lines CX-1 and SW948 hypoxia did not cause HIF-1 $\alpha$ overexpression, nor did it provoke VEGF upregulation. HIF- $\alpha$ associated production of large amounts of VEGF in tumor cells cultured 
in hypoxic conditions seems to depend on the degree of differentiation of the tumor cells. In addition, Koshikawa et al have demonstrated that hypoxia markedly induced VEGF production in high-metastatic, highly-malignant lung and breast carcinoma cell lines, compared to low-metastatic, less-malignant ones (29).

Recent studies indicate that VEGFRs that are expressed on tumor cells support VEGF autocrine signaling which in turn promote tumor cell survival and progression in colorectal cancer. Lesslie et al have also found that migration of the colorectal carcinoma cell line HT-29 was promoted by a functional VEGF/VEGFR-1 interaction (30). Bates et al indentified the VEGF/VEGFR-1 autocrine loop as essential for the survival and migration of colon carcinoma cells LIM 1863 and SW837 (31). Notably, VEGFR-2 expression was not seen. In another study VEGFR-1, but not VEGFR-2, was expressed in seven colorectal carcinoma cell lines (32). In these tumor cells VEGF-induced downstream signaling led to significant motility and invasiveness. In contrast, Kim et al have shown a positive expression of VEGFR-2 in four colorectal carcinoma cell lines supporting the presence of an autocrine VEGF/VEGFR-2 growth pathway (33). Since all colorectal carcinoma cell lines used in our study were negative for the VEGFR-1 and VEGFR-2 transcripts under normoxia and hypoxia the formation of an autocrine VEGF/ VEGFR-1 or VEGF/VEGFR-2 loop is not possible. Taking the results in vitro published so far it seems that autocrine VEGF/VEGFR-1 and VEGF/VEGFR-2 expression in colorectal carcinomas is cell line specific. Interestingly, contrary to the observations in vitro we and others have demonstrated a positive expression of both receptors in colorectal carcinoma tissue specimens in situ (34-36). Consequently, the in vitro expression pattern of the VEGF/VEGFR components could differ from the situation in vivo and might explain the divergent regulation mechanisms presented in the literature. We suggest that VEGF production by cancer cells is not enough for tumoral VEGFR-1 induction. In this context, VEGF production by immunoinflammatory cells of the tumor microenvironment could contribute to VEGFR expression on malignant epithelia in vivo via a paracrine pathway (37). In our study, VEGFR-1 and VEGFR-2 mRNA were also undetectable in A549 and MCF7 cells. The examination of other lung adenocarcinoma cell lines and breast carcinoma cells including MCF7 in vitro provided evidence of positive VEGFR-2 expression $(38,39)$. The conflicting results in the case of MCF7 cells may be due to use of a diverse range of MCF7 lines in different research groups.

VEGFR-3 mRNA and protein were expressed and under hypoxia overexpressed in MCF7 and A549, accompanied by an increased production of its ligand VEGF-C. Notably, MCF7 cells secrete VEGF-C only under hypoxic conditions indicating that hypoxia is an essential stimulating event for an autocrine VEGF-C and VEGFR-3 interaction for this tumor line by inducing VEGF-C production and VEGFR-3 upregulation. vgfr-3 and vegf-c genes have not been found to harbor consensus HIF-binding sites in their promoter/ enhancer regions. Nevertheless, the effect of hypoxia on VEGF-C/VEGFR-3 via the transcription factor HIF-1 $\alpha$ might be incompletely elucidated because in recently published data in breast and osophageal cancer a significant correlation between HIF-1 $\alpha$ and VEGF-C was found (18-20). In accordance with our results in normoxia, Laakkonen et al have also demonstrated lack of VEGF-C and VEGFR-3 expression in many breast carcinoma cell lines, including MCF7 (40). A549 cells, which are known to have strong invasive activity, expressed more abundantly VEGF-C and VEGFR-3 under hypoxia than under normoxia. The functional significance of the elevated expression levels under hypoxia remains to be elucidated. VEGFR-3 and VEGF-C levels were found to be increased in the highly invasive lung cancer cells in comparison with the cells, which have low invasive activity (41). Based on these observations we assume that hypoxia could enhance cancer cell invasiveness and thereby contribute to tumor progression and aggressive behavior.

In the present study, expression of VEGFR-3 mRNA was not observed in any of the colorectal carcinoma cell lines examined. Our findings of absent VEGFR-3 expression in CRC cell lines are consistent with the data published by Onogawa et al for other human colon carcinoma cell lines (42). However, there are now many studies, including our previous study, demonstrating VEGFR-3 expression in colorectal carcinoma tissue in situ $(34,43,44)$. These controversial results between the in vivo situation and the culture conditions underline once more the pivotal role of the tumor microenvironment in determining the expression of angiogenic factors. The receptor-ligand interactions that orchestrate the tumor progression process is also influenced by components of the intratumoral stromal tissue, including fibroblasts, endothelial cells, tumor-associated macrophages and inflammatory cells, which can express VEGF-C and/or VEGF-D (45-48).

Concerning the tumoral secretion of VEGF-D in MCF7 as well as A549 and other lung carcinoma cell lines no constitutive protein expression was seen in our study and in the analyses of other researchers $(49,50)$. Furthermore, our current findings indicate that hypoxia can not induce VEGF-D production.

In conclusion, the present results demostrated the presence of HIF- $1 \alpha$-associated VEGF-C production and induction of its receptor VEGFR-3 in breast and lung carcinomas in vitro. The role of such a possible autocrine loop between VEGF-C/ VEGFR-3 and HIF-1 $\alpha$ for tumor cell survival and progressive behavior remains to be clarified.

\section{References}

1. Harris AL: Hypoxia - a key regulatory factor in tumour growth. Nat Rev Cancer 2: 38-47, 2002.

2. Vaupel P: The role of hypoxia-induced factors in tumor progression. Oncologist 9: 10-17, 2004.

3. Semenza GL: Targeting HIF-1 for cancer therapy. Nat Rev Cancer 3: 721-732, 2003.

4. Forsythe JA, Jiang BH, Iyer NV, Agani F, Leung SW, Koos RD and Semenza GL: Activation of vascular endothelial growth factor gene transcription by hypoxia-inducible factor 1 . Mol Cell Biol 16: 4604-4613, 1996.

5. Ferrara N and Davis-Smyth T: The biology of vascular endothelial growth factor. Endocr Rev 18: 4-25, 1997.

6. Byrne AM, Bouchier-Hayes DJ and Harmey JH: Angiogenic and cell survival functions of vascular endothelial growth factor (VEGF). J Cell Mol Med 9: 777-794, 2005.

7. Mercurio AM, Bachelder RE, Bates RC and Chung J: Autocrine signaling in carcinoma: VEGF and the alpha6beta4 integrin. Semin Cancer Biol 14: 115-122, 2004. 
8. Ferrara N, Gerber HP and Le Couter J: The biology of VEGF and its receptors. Nat Med 9: 669-676, 2003.

9. Gerber HP, Condorelli F, Park J and Ferrara N: Differential transcriptional regulation of the two vascular endothelial growth factor receptor genes. Flt-1, but not Flk-1/KDR, is upregulated by hypoxia. J Biol Chem 272: 23659-23667, 1997.

10. Ono T and Miki C: Factors influencing tissue concentration of vascular endothelial growth factor in colorectal carcinoma. Am J Gastroenterol 95: 1062-1067, 2000.

11. Giatromanolaki A, Koukourakis MI, Turley H, Sivridis E, Harris AL and Gatter KC; Tumour and Angiogenesis Research Group: Phosphorylated KDR expression in endometrial cancer cells relates to HIF1alpha/VEGF pathway and unfavourable prognosis. Mod Pathol 19: 701-707, 2006.

12. Das B, Yeger H, Tsuchida R, Torkin R, Gee MF, Thorner PS, Shibuya M, Malkin D and Baruchel S: A hypoxia-driven vascular endothelial growth factor/Flt1 autocrine loop interacts with hypoxia-inducible factor-1alpha through mitogen-activated protein kinase/extracellular signal-regulated kinase $1 / 2$ pathway in neuroblastoma. Cancer Res 65: 7267-7275, 2005.

13. Alitalo K and Carmeliet P: Molecular mechanisms of lymphangiogenesis in health and disease. Cancer Cell 1: 219-227, 2002.

14. Hu WG, Li JW, Feng B, Beveridge M, Yue F, Lu AG, Ma JJ, Wang ML, Guo Y, Jin XL and Zheng MH: Vascular endothelial growth factors $\mathrm{C}$ and $\mathrm{D}$ represent novel prognostic markers in colorectal carcinoma using quantitative image analysis. Eur Surg Res 39: 229-238, 2007.

15. Mylona E, Alexandrou P, Mpakali A, Giannopoulou I, Liapis G, Markaki S, Keramopoulos A and Nakopoulou L: Clinicopathological and prognostic significance of vascular endothelial growth factors (VEGF)-C and -D and VEGF receptor 3 in invasive breast carcinoma. Eur J Surg Oncol 33: 294-300, 2007.

16. Niki T, Iba S, Tokunou M, Yamada T, Matsuno $\mathrm{Y}$ and Hirohashi S: Expression of vascular endothelial growth factors $\mathrm{A}, \mathrm{B}, \mathrm{C}$ and $\mathrm{D}$ and their relationships to lymph node status in lung adenocarcinoma. Clin Cancer Res 6: 2431-2439, 2000 .

17. Su JL, Yen CJ, Chen PS, Chuang SE, Hong CC, Kuo IH, Chen HY, Hung MC and Kuo ML: The role of the VEGF-C/ VEGFR-3 axis in cancer progression. Br J Cancer 96: 541-545, 2007.

18. Schoppmann SF, Fenzl A, Schindl M, Bachleitner-Hofmann T, Nagy K, Gnant M, Horvat R, Jakesz R and Birner P: Hypoxia inducible factor-1alpha correlates with VEGF-C expression and lymphangiogenesis in breast cancer. Breast Cancer Res Treat 99: 135-141, 2006.

19. Okada K, Osaki M, Araki K, Ishiguro K, Ito H and Ohgi S: Expression of hypoxia-inducible factor (HIF-1alpha), VEGF-C and VEGF-D in non-invasive and invasive breast ductal carcinomas. Anticancer Res 25: 3003-3009, 2005.

20. Katsuta M, Miyashita M, Makino H, Nomura T, Shinji S, Yamashita K, Tajiri T, Kudo M, Ishiwata T and Naito Z: Correlation of hypoxia inducible factor-1alpha with lymphatic metastasis via vascular endothelial growth factor-C in human esophageal cancer. Exp Mol Pathol 78: 123-130, 2005.

21. Teng X, Li D and Johns RA: Hypoxia upregulates mouse vascular endothelial growth factor D promoter activity in rat pulmonary microvascular smooth-muscle cells. Chest 121: S82-S83, 2002.

22. Currie MJ, Hanrahan V, Gunningham SP, Morrin HR, Frampton C, Han C, Robinson BA and Fox SB: Expression of vascular endothelial growth factor $\mathrm{D}$ is associated with hypoxia inducible factor (HIF-1alpha) and the HIF-1alpha target gene DEC1, but not lymph node metastasis in primary human breast carcinomas. J Clin Pathol 57: 829-834, 2004.

23. Zhong H, Mabjeesh N, Willard M and Simons J: Nuclear expression of hypoxia-inducible factor 1alpha protein is heterogeneous in human malignant cells under normoxic conditions. Cancer Lett 181: 233-238, 2002.

24. Dang DT, Chen F, Gardner LB, Cummins JM, Rago C, Bunz F, Kantsevoy SV and Dang LH: Hypoxia-inducible factor-1alpha promotes non-hypoxia-mediated proliferation in colon cancer cells and xenografts. Cancer Res 66: 1684-1693, 2006.

25. Shi YH, Bingle L, Gong LH, Wang YX, Corke KP and Fang WG: Basic FGF augments hypoxia induced HIF-1-alpha expression and VEGF release in T47D breast cancer cells. Pathology 39: 396-400, 2007.
26. Mizukami Y, Li J, Zhang X, Zimmer MA, Iliopoulos O and Chung DC: Hypoxia-inducible factor-1-independent regulation of vascular endothelial growth factor by hypoxia in colon cancer. Cancer Res 64: 1765-1772, 2004.

27. Kuwai T, Kitadai Y, Tanaka S, Onogawa S, Matsutani N, Kaio E, Ito $M$ and Chayama $\mathrm{K}$ : Expression of hypoxiainducible factor-1alpha is associated with tumor vascularization in human colorectal carcinoma. Int J Cancer 105: 176-181, 2003.

28. Boussat S, Eddahibi S, Coste A, Fataccioli V, Gouge M, Housset B, Adnot S and Maitre B: Expression and regulation of vascular endothelial growth factor in human pulmonary epi-thelial cells. Am J Physiol Lung Cell Mol Physiol 279: 371-378, 2000.

29. Koshikawa N, Iyozumi A, Gassmann M and Takenaga K: Constitutive upregulation of hypoxia-inducible factor-1alpha mRNA occurring in highly metastatic lung carcinoma cells leads to vascular endothelial growth factor overexpression upon hypoxic exposure. Oncogene 22: 6717-6724, 2003.

30. Lesslie DP, Summy JM, Parikh NU, Fan F, Trevino JG, Sawyer TK, Metcalf CA, Shakespeare WC, Hicklin DJ, Ellis LM and Gallick GE: Vascular endothelial growth factor receptor-1 mediates migration of human colorectal carcinoma cells by activation of Src family kinases. Br J Cancer 94: 1710-1717, 2006.

31. Bates RC, Goldsmith JD, Bachelder RE, Brown C, Shibuya M, Oettgen P and Mercurio AM: Flt-1-dependent survival characterizes the epithelial-mesenchymal transition of colonic organoids. Curr Biol 13: 1721-1727, 2003.

32. Fan F, Wey JS, McCarty MF, Belcheva A, Liu W, Bauer TW, Somcio RJ, Wu Y, Hooper A, Hicklin DJ and Ellis LM: Expression and function of vascular endothelial growth factor receptor-1 on human colorectal cancer cells. Oncogene 24: 2647-2653, 2005

33. Kim SJ, Seo JH, Lee YJ, Yoon JH, Choi CW, Kim BS, Shin SW, Kim YH and Kim JS: Autocrine vascular endothelial growth factor/vascular endothelial growth factor receptor-2 growth pathway represents a cyclooxygenase-2-independent target for the cyclooxygenase-2 inhibitor NS-398 in colon cancer cells. Oncology 68: 204-211, 2005.

34. Simiantonaki N, Taxeidis M, Jayasinghe $\mathrm{C}$ and Kirkpatrick CJ: Epithelial expression of VEGF receptors in colorectal carcinomas and their relationship to metastatic status. Anticancer Res 27: 3245-3250, 2007.

35. Andre T, Kotelevets L, Vaillant JC, Coudray AM, Weber L, Prevot S, Parc R, Gespach C and Chastre E: VEGF, VEGF-B, VEGF-C and their receptors KDR, FLT- 1 and FLT-4 during the neoplastic progression of human colonic mucosa. Int $\mathbf{J}$ Cancer 86: 174-181, 2000.

36. Duff SE, Jeziorska M, Rosa DD, Kumar S, Haboubi N, Sherlock D, O'Dwyer ST and Jayson GC: Vascular endothelial growth factors and receptors in colorectal cancer: implications for anti-angiogenic therapy. Eur J Cancer 42: 112-117, 2006.

37. Fukuyama T, Ichiki Y, Yamada S, Shigematsu Y, Baba T, Nagata Y, Mizukami M, Sugaya M, Takenoyama M, Hanagiri T, Sugio $\mathrm{K}$ and Yasumoto $\mathrm{K}$ : Cytokine production of lung cancer cell lines: correlation between their production and the inflammatory/immunological responses both in vivo and in vitro. Cancer Sci 98: 1048-1054, 2007.

38. Tanno S, Ohsaki Y, Nakanishi K, Toyoshima E and Kikuchi K Human small cell lung cancer cells express functional VEGF receptors, VEGFR-2 and VEGFR-3. Lung Cancer 46: 11-19, 2004

39. Tian X, Song S, Wu J, Meng L, Dong Z and Shou C: Vascular endothelial growth factor: acting as an autocrine growth factor for human gastric adenocarcinoma cell MGC803. Biochem Biophys Res Commun 286: 505-512, 2001.

40. Laakkonen P, Waltari M, Holopainen T, Takahashi T, Pytowski B, Steiner P, Hicklin D, Persaud K, Tonra JR, Witte L and Alitalo K: Vascular endothelial growth factor receptor 3 is involved in tumor angiogenesis and growth. Cancer Res 67: 593-599, 2007.

41. Su JL, Yang PC, Shih JY, Yang CY, Wei LH, Hsieh CY, Chou $\mathrm{CH}$, Jeng YM, Wang MY, Chang KJ, Hung MC and Kuo ML: The VEGF-C/Flt-4 axis promotes invasion and metastasis of cancer cells. Cancer Cell 9: 209-223, 2006.

42. Onogawa S, Kitadai Y, Tanaka S, Kuwai T, Kimura S and Chayama K: Expression of VEGF-C and VEGF-D at the invasive edge correlates with lymph node metastasis and prognosis of patients with colorectal carcinoma. Cancer Sci 95 : 32-39, 2004 
43. Parr C and Jiang WG: Quantitative analysis of lymphangiogenic markers in human colorectal cancer. Int J Oncol 23: 533-539, 2003.

44. Hanrahan V, Currie MJ, Gunningham SP, Morrin HR, Scott PA, Robinson BA and Fox SB: The angiogenic switch for vascular endothelial growth factor (VEGF)-A, VEGF-B, VEGF-C and VEGF-D in the adenoma-carcinoma sequence during colorectal cancer progression. J Pathol 200: 183-194, 2003.

45. Krishnan J, Kirkin V, Steffen A, Hegen M, Weih D, Tomarev S, Wilting $J$ and Sleeman JP: Differential in vivo and in vitro expression of vascular endothelial growth factor (VEGF)-C and VEGF-D in tumors and its relationship to lymphatic metastasis in immunocompetent rats. Cancer Res 63: 713-722, 2003.

46. Schoppmann SF, Birner P, Stöckl J, Kalt R, Ullrich R, Caucig C, Kriehuber E, Nagy K, Alitalo K and Kerjaschki D: Tumor-associated macrophages express lymphatic endothelial growth factors and are related to peritumoral lymphangiogenesis. Am J Pathol 161: 947-956, 2002.
47. Esposito I, Menicagli M, Funel N, Bergmann F, Boggi U, Mosca F, Bevilacqua G and Campani D: Inflammatory cells contribute to the generation of an angiogenic phenotype in pancreatic ductal adenocarcinoma. J Clin Pathol 57: 630-636, 2004.

48. Joukov V, Pajusola K, Kaipainen A, Chilov D, Lahtinen I, Kukk E, Saksela O, Kalkkinen N and Alitalo K: A novel vascular endothelial growth factor, VEGF-C, is a ligand for the Flt4 (VEGFR-3) and KDR (VEGFR-2) receptor tyrosine kinases. EMBO J 15: 290-298, 1996.

49. Akahane M, Akahane T, Matheny SL, Shah A, Okajima E and Thorgeirsson UP: Vascular endothelial growth factor-D is a survival factor for human breast carcinoma cells. Int $\mathbf{J}$ Cancer 118: 841-849, 2006.

50. He Y, Kozaki K, Karpanen T, Koshikawa K, Yla-Herttuala S, Takahashi T and Alitalo K: Suppression of tumor lymphangiogenesis and lymph node metastasis by blocking vascular endothelial growth factor receptor 3 signaling. J Natl Cancer Inst 94: 819-825, 2002. 